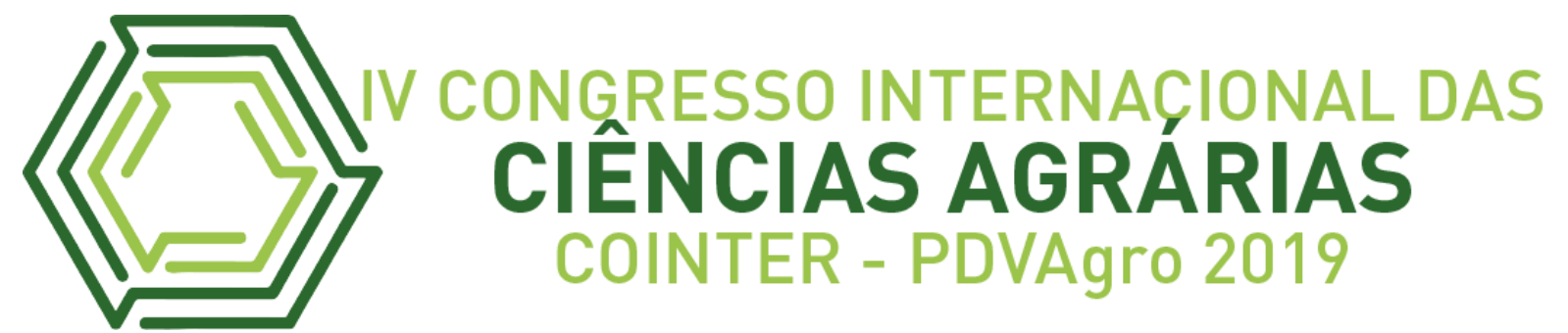

\title{
UTILIZAÇÃO DE SOFTWARES DE SISTEMA DE INFORMAÇÃO GEOGRÁFICA EM DADOS DA PRODUÇÃO DA APICULTURA E MELIPONICULTURA NO ESTADO DO PARÁ
}

\author{
USO DEL SOFTWARE DEL SISTEMA DE INFORMACIÓN GEOGRÁFICA EN \\ LOS DATOS DE LA APICULTURA Y LA PRODUCCIÓN DE MELIPONICULTURA \\ EN EL ESTADO DE PARÁ
}

\section{USE OF GEOGRAPHICAL INFORMATION SYSTEM SOFTWARE ON BEEKEEPING AND MELIPONICULTURE PRODUCTION DATA IN THE STATE OF PARÁ}

\author{
Apresentação: Comunicação Oral \\ Maicon Silva Farias ${ }^{1}$; Thalisson Johann Michelon de Oliveira ${ }^{2}$; André Wender Azevedo \\ Ribeiro $^{3}$; Eduarda Cavalcante Silva ${ }^{4}$; Pâmela Emanuelle Sousa e Silva ${ }^{5}$
}

DOI: https://doi.org/10.31692/2526-7701.IVCOINTERPDVAgro.2019.0039

\begin{abstract}
Resumo
O objetivo deste trabalho foi demostrar os dados da produção e exportação do mel no Estado do Pará, evidenciando os insumos de produção e comercialização, comercialização e mercado, características produtivas e os entraves e gargalos desta produção. Desde o início da humanidade o mel foi utilizado para a alimentação humana para sua sobrevivência, o que ao longo dos anos o próprio ser humano foi aprendendo a manejar as produtoras deste alimento. A meliponicultura é considerada uma atividade tradicional amplamente difundida no Brasil, ainda é bastante artesanal, com práticas rudimentares e muito variável aos meliponicultores. Os dados referentes foram coletados dos sites do IBGE, MDIC e do Imazon do ano de 2010 até 2019. Os dados foram trabalhados no Microsoft Excel 2016 para seleção da categoria e do período e criados gráficos de oscilação da cadeia produtiva do mel, e alguns dados exportados para o software QGIS (Versão 3.2), para a elaboração de mapas temáticos com dados de cada município do estado. Para o entendimento dos insumos e entraves da cadeia produtiva, foram realizados bate-papo com os dirigentes e produtores da Associação de Criadores e Criadoras de Abelhas Melífera do Município de Igarapé-Açu e com os dirigentes do Instituto Peabiru. A região Norte é pouca produtora quando se compara com os outros estados, com 1,9\% de toda a produção nacional, o município de Alenquer foi o que apresentou maior número de
\end{abstract}

\footnotetext{
${ }^{1}$ Mestre em Gestão Ambiental, Universidade Federal Rural da Amazônia, maiconfarias11@gmail.com

${ }^{2}$ Agronomia, Universidade Federal Rural da Amazônia, thalissonjohann@ hotmail.com

${ }^{3}$ Agronomia, Universidade Federal Rural da Amazônia, andre.ecolampy2@gmail.com

${ }^{4}$ Agronomia, Universidade Federal Rural da Amazônia, eduardacavalcante1212@gmail.com

${ }^{5}$ Agronomia, Universidade Federal Rural da Amazônia, pamemanuelle2000@gmail.com
} 
estabelecimentos com 91 locais de produção. O valor de produção do Estado do Pará no ano de 2010 a 2017 na apicultura foi em torno de 46 milhões de reais, sendo que a exportação de mel no Pará teve seu ápice no ano de $2018 \mathrm{com} 47 \mathrm{~kg}$ líquidos e com a previsão de $40 \mathrm{~kg}$ líquidos para este ano de 2019. Ademais muitos dos produtos oriundos das abelhas são considerados produtos artesanais conforme a Lei $\mathrm{N}^{\circ} 7.565$ de 25 de outubro de 2011 . O mel produzido pelas abelhas é apenas o topo da pirâmide, pois o valor real destes insetos está na importância ecológica e ambiental que as mesmas fazer através da polinização. O mercado consumidor de mel existe, só que a demanda do produto licenciado está em falta, devido à grande parte da produção ir para o mercado informal.

Palavras-Chave: Mel artesanal, AMIGA, Instituto Peabiru, QGIS.

\section{Resumen}

El objetivo de este trabajo fue demostrar los datos de producción y exportación de miel en el Estado de Pará, mostrando los insumos de producción y comercialización, comercialización y mercado, características de producción y las barreras y cuellos de botella de esta producción. Desde el comienzo de la humanidad, la miel se ha utilizado para el consumo humano para su supervivencia, que a lo largo de los años el ser humano ha aprendido a administrar a los productores de este alimento. La meliponicultura se considera una actividad tradicional generalizada en Brasil, todavía es bastante artesanal, con prácticas rudimentarias y muy variable para los meliponiculturistas. Los datos se recopilaron de los sitios web de IBGE, MDIC e Imazon de 2010 a 2019. Los datos se trabajaron en Microsoft Excel 2016 para seleccionar la categoría y el período, y se crearon gráficos de oscilación de la cadena de producción de miel y algunos datos. exportado al software QGIS (Versión 3.2), para la preparación de mapas temáticos con datos de cada municipio del estado. Para comprender los insumos y las barreras en la cadena de producción, se mantuvieron conversaciones con los líderes y productores de la Asociación de Productores y Criadores de Abejas de Miel del Municipio de Igarapé-Açu y con los líderes del Instituto Peabiru. La región del norte es un productor pobre en comparación con otros estados, con el 1.9\% de toda la producción nacional, el municipio de Alenquer fue el que tuvo el mayor número de establecimientos con 91 sitios de producción. El valor de la producción del Estado de Pará en el año 2010 a 2017 en la apicultura fue de alrededor de 46 millones de reales, y la exportación de miel en Pará tuvo su pico en 2018 con 47 kg netos y con un pronóstico de 40 kilogramos netos para este año 2019. Además, muchos de los productos de abejas se consideran hechos a mano de acuerdo con la Ley $\mathrm{N}^{\circ} 7.565$ del 25 de octubre de 2011. La miel producida por las abejas es solo la parte superior de la pirámide porque el valor real de estos insectos Es en la importancia ecológica y ambiental que hacen a través de la polinización. El mercado de consumo de miel existe, pero falta la demanda del producto con licencia, porque gran parte de la producción se destina al mercado informal.

Palabras Clave: Miel artesanal, AMIGA, Instituto Peabiru, QGIS.

\footnotetext{
Abstract

The objective of this work was to demonstrate the data of honey production and export in the State of Pará, showing the production and marketing inputs, marketing and market, production
} 
characteristics and the barriers and bottlenecks of this production. Since the beginning of humanity honey has been used for human consumption for its survival, which over the years the human being has learned to manage the producers of this food. Meliponiculture is considered a traditional activity widespread in Brazil, is still quite artisanal, with rudimentary practices and very variable to meliponiculturists. The data were collected from the IBGE, MDIC and Imazon websites from 2010 to 2019. The data were worked in Microsoft Excel 2016 to select the category and period and graphs were created of oscillation of the honey production chain, and some data. exported to QGIS software (Version 3.2), for the preparation of thematic maps with data from each municipality of the state. In order to understand the inputs and barriers in the production chain, discussions were held with the leaders and producers of the Association of Honey Bee Producers and Breeders of the Municipality of Igarapé-Açu and with the leaders of the Peabiru Institute. The northern region is a poor producer when compared to other states, with $1.9 \%$ of all national production, the municipality of Alenquer was the one with the largest number of establishments with 91 production sites. The production value of the State of Pará in the year 2010 to 2017 in beekeeping was around 46 million reais, and the export of honey in Pará had its peak in 2018 with $47 \mathrm{~kg}$ net and with the forecast of 40 net kilograms for this year 2019. In addition many of the bee products are considered to be handcrafted according to Law No. 7.565 of October 25, 2011. Honey produced by bees is only the top of the pyramid because the real value of these insects it is in the ecological and environmental importance that they make through pollination. The honey consumer market exists, but the demand for the licensed product is lacking, because much of the production goes to the informal market.

Keywords: Artisanal honey, AMIGA, Institute Peabiru, QGIS.

\section{Introdução}

A cadeia produtiva visa estudar um conjunto de fases consecutivas ao longo de diversas transformações, ou seja, baseia-se desde o produtor até o consumidor final (CASTRO et al, 2002). Logo, a cadeia produtiva agrega a caracterização dessa cadeia, insumos de produção e comercialização, comercialização e mercado, características produtivas e os entraves e gargalos desta produção.

Desde o início da humanidade o mel foi utilizado para a alimentação humana para sua sobrevivência, o que ao longo dos anos o próprio ser humano foi aprendendo a manejar as produtoras deste alimento. Mas tardar, com o sedentarismo humano e com a fixação no campo a atividade evoluiu exponencialmente chegando a se tornar a atividade principal de muitas regiões, e fonte de renda de muitas famílias rurais (ZANDONADI et al, 2005).

A flora brasileira possui uma vasta biodiversidade, o que para Sabbag et al (2011) é uma vantagem, pois possibilita a coleta do mel em diversos tempos de floração, com diferentes gostos, aromas e cores. 
Consoante Duarte (2017), a produção do mel é uma prática de origem animal com pouco dano ambiental e uma ótima fonte de renda, ou seja, possibilita a utilização permanente dos recursos naturais trazendo lucratividade para o produtor. Além de que, pode-se extrair também outros produtos, tais quais: pólen, própolis, geleia, comercialização de enxames ou rainhas.

A principal atividade da apicultura é a extração do mel (PASCHOALINO et al, 2014), devido ser o produto mais consumido, visto que o mel tem muitos benefícios para a saúde. Com isso, de acordo com o Almeida et al (2009), o mel tem insumos específicos como a centrífuga, decantador, equipamentos laboratoriais para medir o $\mathrm{pH}$, embalagens plásticas, rótulos, entre outros.

Conforme Silva et al (2003), os Sistemas de Informações Geográficas (GIS) são softwares de informação espacial que permitem a facilitação de informações exatas com rapidez, menos onerosos e alta exatidão do resultado se utilizado corretamente.

Na percepção do Ribeiro et al (2013), a cadeia produtiva da apicultura é baseada na criação de abelhas para a produção das matérias primas, como mel, própolis, cera, o pólen, entre outras. Dessa forma, cada matéria prima tem seu mercado de consumo, no entanto, os insumos necessários para obter os produtos provenientes das abelhas são as caixas feitas de madeira que as abelhas ficam alojadas, sendo chamadas de colmeias, baldes em aço inox, derretedor de cera, incrustador de cera, cilindro alveolar, entre outros.

Este presente estudo teve como objetivo caracterizar a o mercado regional paraense na apicultura e meliponicultura evidenciando os insumos de produção e comercialização, comercialização e mercado, características produtivas e os entraves e gargalos desta produção desde o produtor até o consumidor final através de softwares de linguagem de programação estatística (R-Studio) e sistema de informação geográfica (QGIS).

\section{Fundamentação Teórica}

O autor Vilela (2000), estudou os principais resultados da cadeia produtiva do mel de abelhas do Estado do Piauí fazendo uma pesquisa socioeconômica através de entrevistas desde os produtores até os consumidores. E um dos principais entraves foi a falta de um fórum comum para debates entre todos os integrantes dessa cadeia.

Souza (2006) fez um estudo acerca da cadeia produtiva do mel em Alagoas, visando fazer um levantamento de dados acerca da apicultura e suas características de produção, principalmente, os entraves e os insumos. Ademais, foi analisado as características econômicas, 
ambientais e sociais do estado de Alagoas, para ter uma noção geral de como funcionam as atividades agrícolas no local estudado. Para obtenção destas informações, foram aplicados questionários e entrevistas para cooperativas de apicultores locais. Após os estudos acerca da cadeia produtiva do mel, o autor concluiu que essa atividade influência na preservação das espécies vegetais, além de gerar renda para os apicultores, no entanto, é necessário a adequação ao que os órgãos de fiscalização exigem, para ter o licenciamento para comercialização em pontos de venda, como supermercados, entre outros.

Na figura abaixo temos as variáveis que estão compondo o sistema que podem ajudar ou atrapalhar o desenvolvimento da cadeia produtiva do mel, elaborado com base na entrevista de campo com os produtores da cidade de Igarapé - Açu.

Figura 1: Variáveis que compõem o sistema da cadeia produtiva.

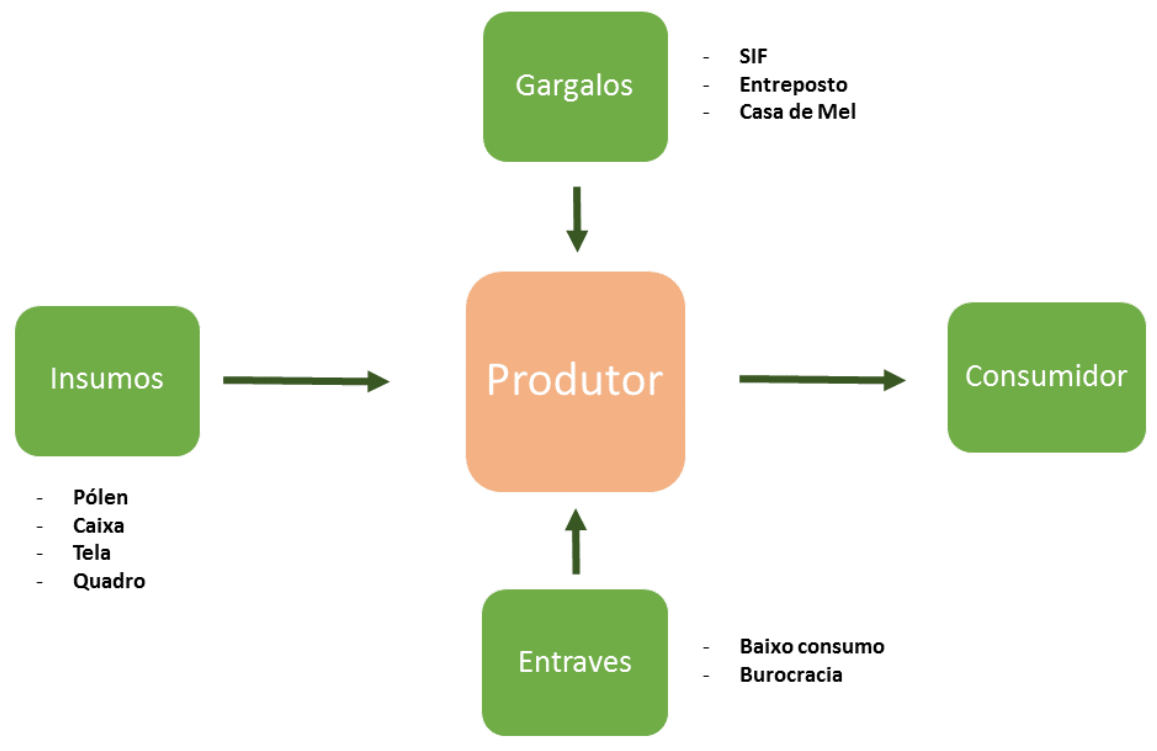

Fonte: Própria (2019)

A meliponicultura é considerada uma atividade tradicional amplamente difundida no Brasil, ainda é bastante artesanal, com práticas rudimentares e muito variável aos meliponicultores, principalmente no estado do Rio Grande do Norte, por esse motivo foi realizado um estudo com o objetivo de verificar o real estágio da criação das abelhas sem ferrão e produção de mel. O autor aplicou questionários estruturados em diferentes cidades da região 
e segundo os dados obtidos pela pesquisa, ficou evidenciado que uma das principais dificuldades encontradas pelas pessoas que trabalham com meliponicultura é a falta de assistência técnica para orientá-los, uma melhor capacitação técnica do meliponicultor e o manejo, sendo que a produtividade da cadeia de meliponicultura é aumentada (MAIA, 2013).

Segundo Balbino et al (2015), que estudou a identificação e percepção das dificuldades que os produtores têm em adotar práticas mais responsáveis social e ambientalmente correta no Mato Grosso do Sul. Os autores fizeram uma pesquisa de método qualitativo, com entrevista semiestruturada com pessoas que participam da Associação de Apicultores para que pudessem ter um parâmetro de como os apicultores daquela região se comportavam diante da responsabilidade social em relação ao manejo da produção de mel. Foi constatado que a apicultura é uma atividade lucrativa, porém um dos gargalos enfrentado pelos apicultores do Mato Grosso do Sul é estar de acordo com as regras da Legislação Brasileira, isso impede que os seus produtos sejam comercializados formalmente no mercado.

\section{Metodologia}

Os dados referentes foram coletados dos sites do Instituto Brasileiro de Geografia e Estatística (IBGE), por meio, da plataforma SIDRA (banco de dados), Ministério da Indústria Comércio Exterior e Serviços (MDIC) e do Instituto do Homem e Meio Ambiente da Amazônia (Imazon) com dados do período de 2010 a 2019 no estado do Pará (figura 2), ou seja, os dados utilizados no estudo foram todos secundários.

Após a coleta, os dados foram trabalhados no Microsoft Excel 2016 para seleção da categoria e do período e criados gráficos de oscilação da cadeia produtiva do mel, e outros foram exportados para o QGIS (Versão 3.8.2), software de informação geográfica para a elaboração de mapas temáticos com dados de cada município do estado, tal softwares está disponível para utilização gratuita. Nos cartogramas, os shapefiles foram adquiridos através do site do IBGE e Ideflor. 
Figura 2: Mapa de localização do Estado do Pará.
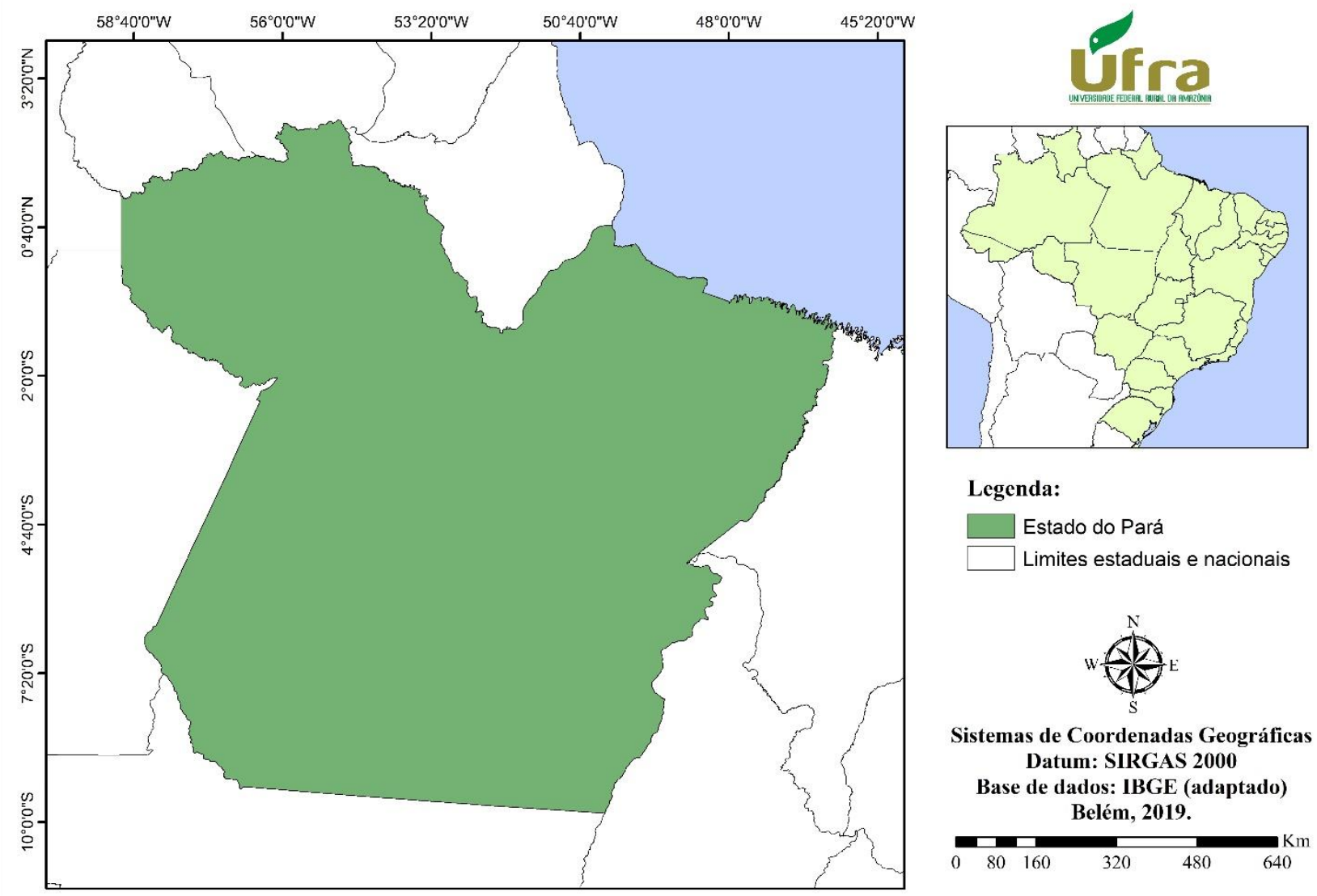

Fonte: Própria (2019).

Para o entendimento dos insumos e entraves da cadeia produtiva do mel no Pará, foram realizados bate-papos com os produtores e dirigentes da Associação de Criadores e Criadoras de Abelhas Melífera do Município de Igarapé-Açu (AMIGA) que é uma associação de comercialização do mel de abelha do gênero Apis, e um bate-papo com os dirigentes do Instituto Peabiru, responsável por auxiliar os meliponicultores do estado para a produção e venda desse mel.

\section{Resultados e Discussão}

De acordo com dados do Instituto Brasileiro de Geografia e Estatística, no ano de 2017 os maiores produtores de mel se encontram na região Sul e parte de Sudeste e Nordeste, sendo que na região Sul encontram-se 39,7\% de toda a produção nacional. A região Norte apresenta 
baixa produção quando comparada as demais regiões, com 1,9\% de toda a produção nacional, um quantitativo muito baixo, como pode ser visto na figura abaixo sobre a produção em mil toneladas.

O estado do Pará tem um conhecimento ótimo para o desenvolvimento das atividades de manejo com abelhas sociais, tanto é que o Pará é considerado o maior produtor do Norte do país (SANTOS et al, 2018). Porém, a região Norte ainda não se destaca a nível nacional, devido a tecnologia usada para a produção de mel, e o próprio mercado apresenta dificuldades. O que para os produtores da AMIGA e do Instituto Peabiru, esta dificuldade é relacionada a dificuldade da venda deste mel, haja vista que a legalização através de fiscalizações feitas pelos órgãos públicos é um requisito para a venda em supermercados e farmácias, e sem a comprovação desta legalização, dificulta até mesmo a exportação do produto.

Figura 3: Produção de mel em mil toneladas no ano de 2017.

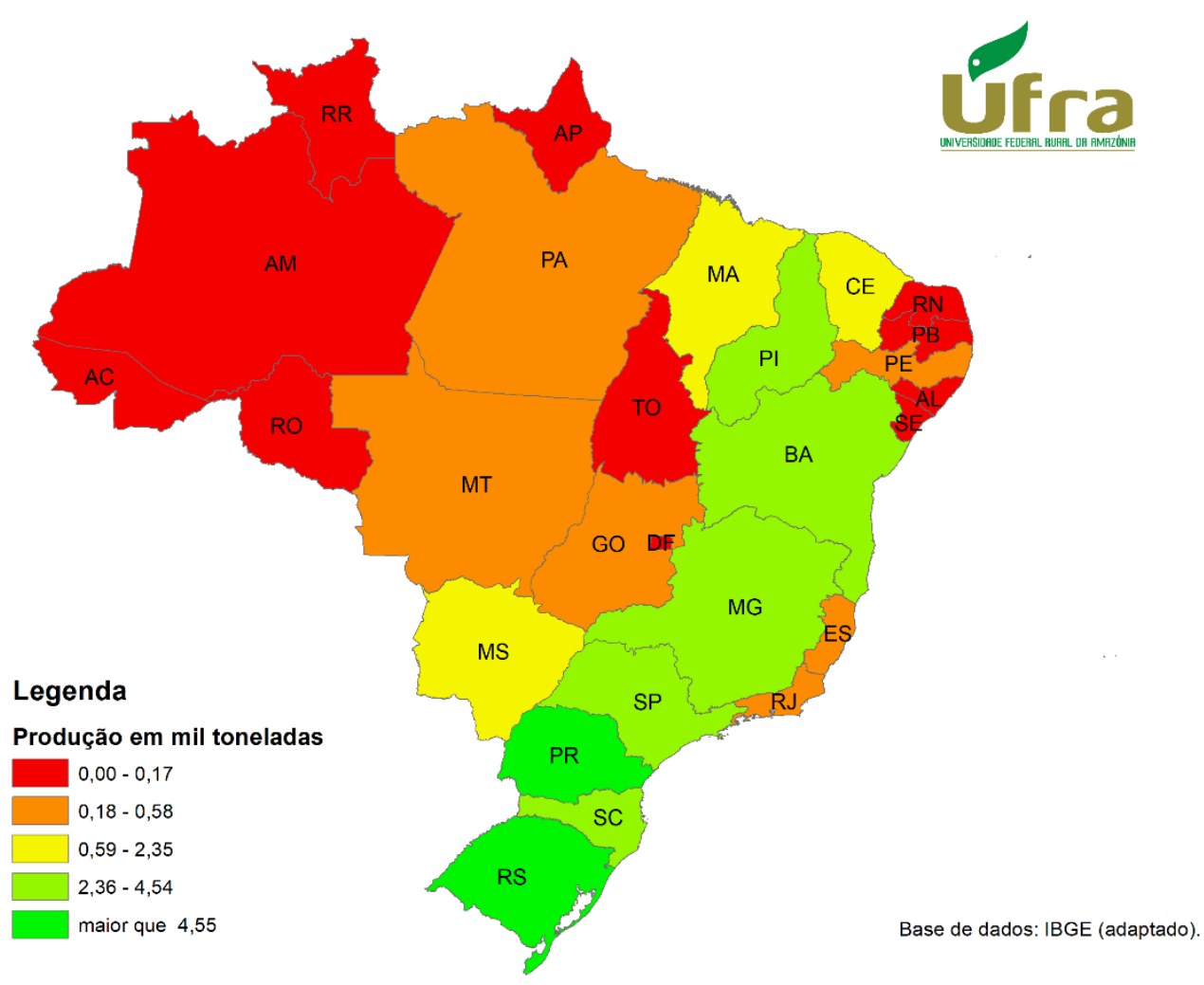

Fonte: Própria (2019). 
A figura 4 representa o comparativo dos três maiores produtores nacionais, em relação ao estado do Pará no período de 2011 a 2017. Neste gráfico, observa-se que o maior produtor nacional de mel é o Rio Grande do Sul com 6.320 toneladas, seguido pelo Paraná com 5.930 toneladas. Enquanto o estado do Pará neste período, a produção teve um leve aumento na produção passando de 410 toneladas para 500 toneladas. A produção de mel nesses estados vem crescendo como atividade econômica, apesar de despontar na exportação (WOLFF, 2018).

Figura 4: Ranking dos 3 maiores produtores nacionais.

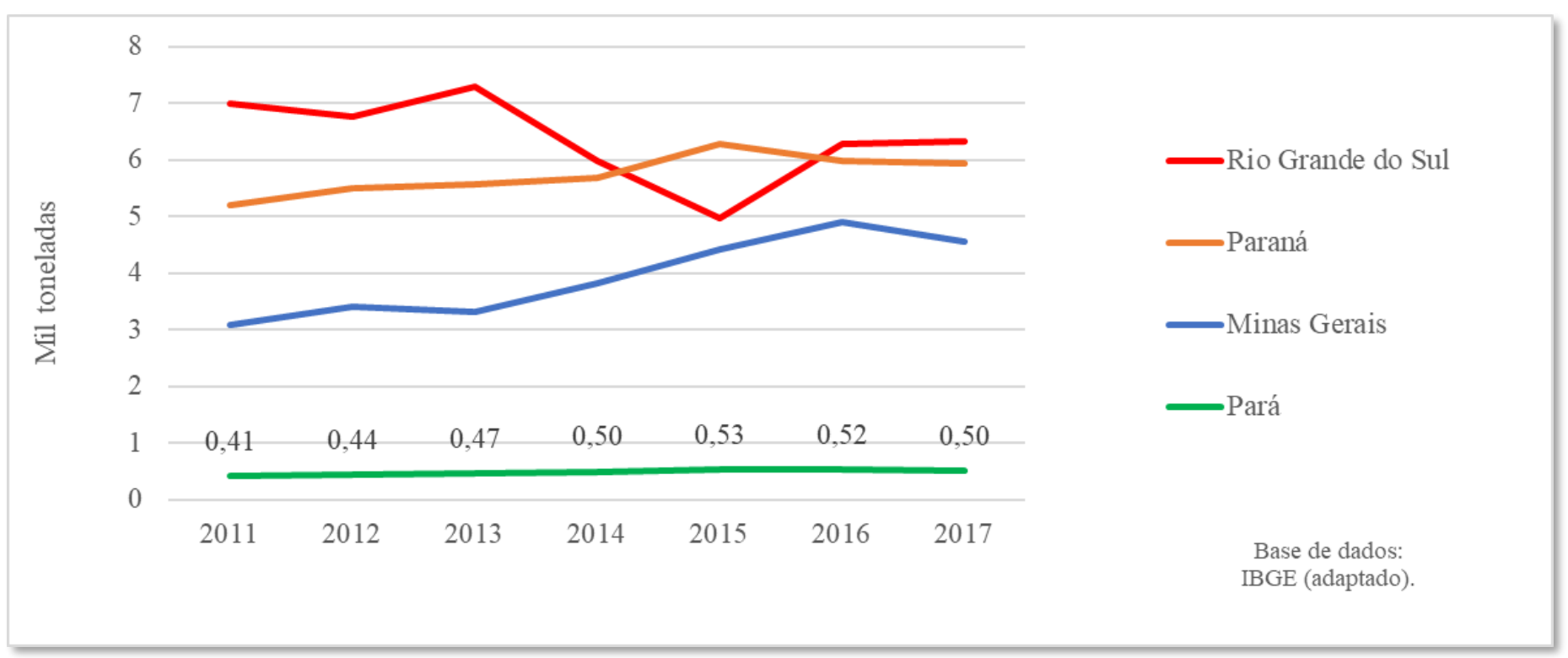

Fonte: Própria (2019).

Hodiernamente no Brasil, estima-se ter em torno de 350 mil apicultores (WOLFF, 2018), e 100 mil estabelecimentos agropecuários relacionados a apicultura, sendo que menos de $1 \%$ desses estabelecimentos se encontram no estado do Pará consoante dados obtidos do Censo Agropecuário.

Além disso, faz-se necessário ressaltar os municípios do Pará. Com base nos dados do Censo Agropecuário de 2017, é possível destacar os municípios que possuem maior número de estabelecimento rurais com produção de mel, sendo eles Santarém, Pau D’arco, Alenquer, Eldorado do Carajás, Belterra, Ourém, Tracuateua, Igarapé-Açu, Óbidos, Viseu, Augusto Corrêa e Bragança. O município com maior número de estabelecimentos foi o Alenquer, na região do baixo amazonas, com 91 estabelecimentos com apiários como pode ser visto no cartograma da figura 5. 
Figura 5: Quantidade de estabelecimentos por municípios no ano de 2017.

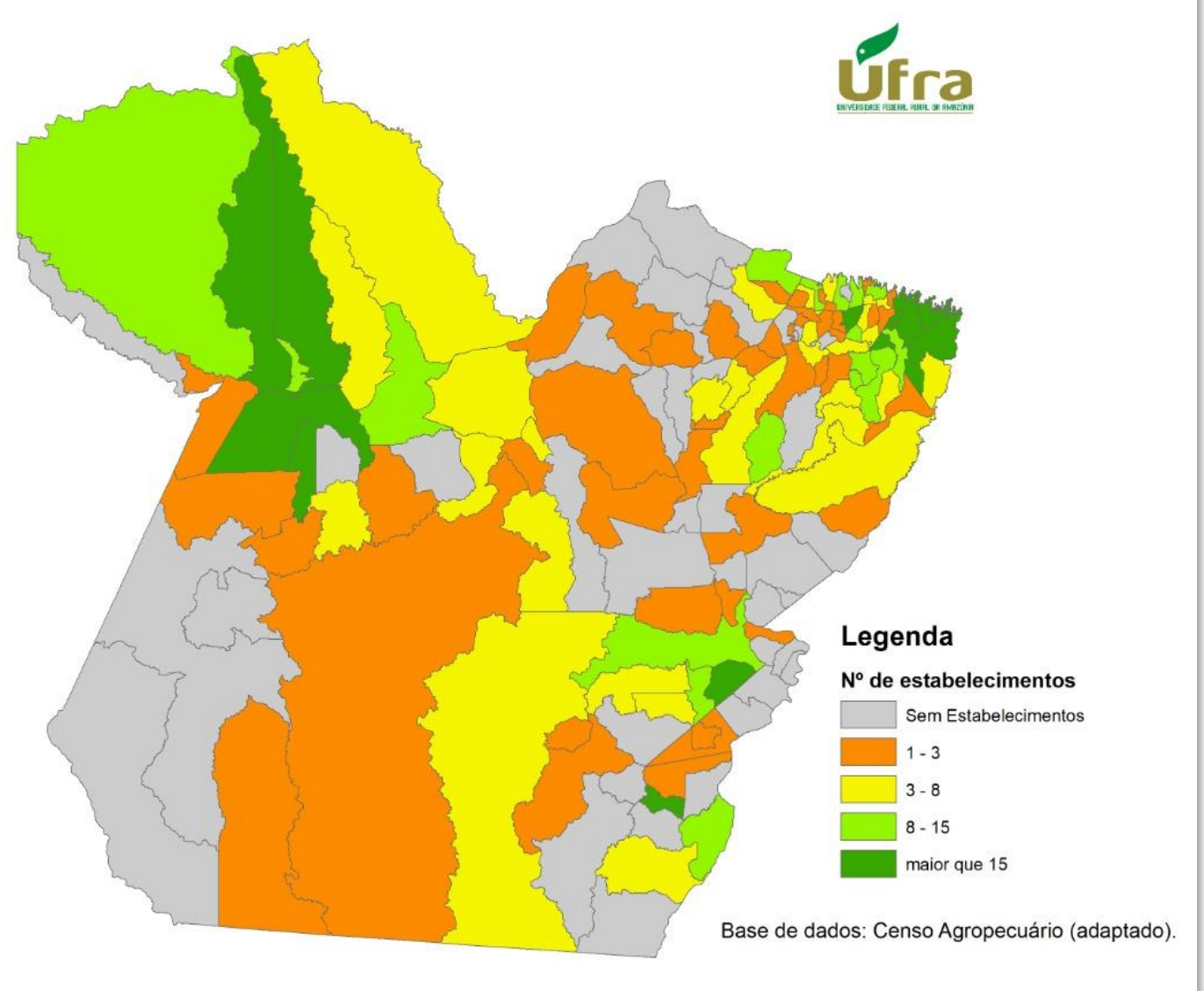

Fonte: Própria (2019).

A figura 6 representa a média das produções do ano de 2010 a 2017 dos estados da região Norte. O Pará apresentou 480 toneladas de produção, já os outros estados apresentaram juntos 450 toneladas, ou seja, só o estado do Pará produz o equivalente a $51 \%$ de toda a produção da região.

Muitos dos produtos oriundos das abelhas são considerados produtos artesanais. Conforme a Lei estadual $\mathrm{N}^{\circ} 7.565$ de 25 de outubro de 2011. O produto de origem animal como o mel de abelha é considerado artesanal. Quando a produção anual for de até 11 toneladas de mel do gênero Apis e 4 toneladas de Melipona são considerados produtos não-industriais e característicos da cultura regional e cultural paraense. 
Quando relacionada os dados de produção com o número de estabelecimento com apiário, verificamos que a produção paraense está na média de 481 toneladas para 900 estabelecimentos, logo podemos inferir que a produção de mel no estado é basicamente artesanal ao que afirma da lei $\mathrm{N}^{\circ} 7567 / 2011$. Sendo que os produtores possam solicitar apoio para que a sua produção seja certificada como produto artesanal e possa adentrar ao mercado formal. Visto que, por falta de regularização os produtores realizam a venda da produção no mercado informal, nas feiras de produtos da agricultura familiar, feiras livres, entre outros.

Figura 6: Médias das produções do ano de 2010 a 2017 na região Norte.

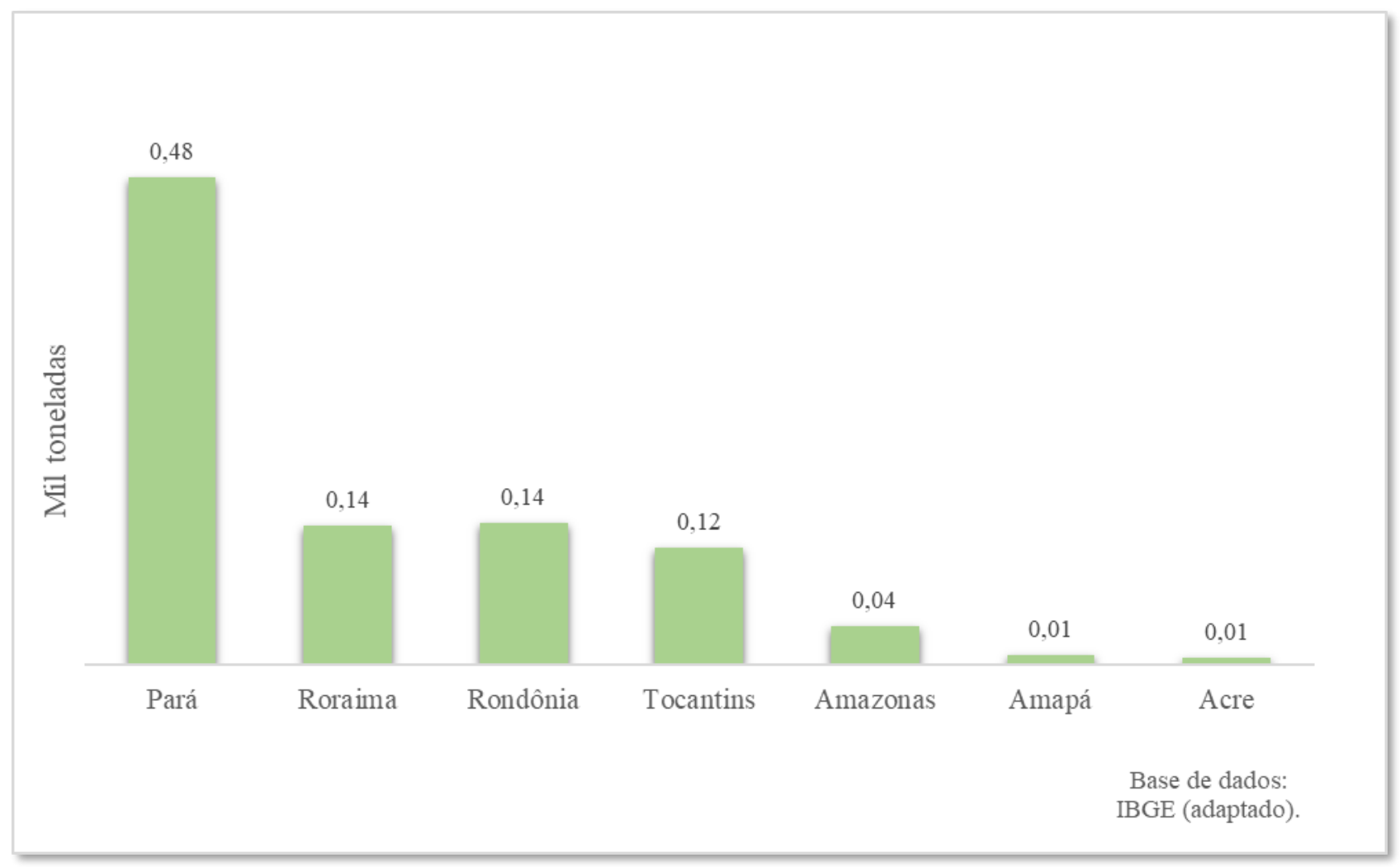

Fonte: Própria (2019).

O valor de produção do estado do Pará no ano de 2010 a 2017 na apicultura foi em torno de 46 milhões de reais (figura 7). O que para Silva et al (2006) é uma atividade rentável, pois o autor constatou que a meliponicultura proporciona lucratividade desde o primeiro ano de produção, trazendo benefícios para a propriedade em que se encontra a caixa com o enxame pois as abelhas fazem a polinização local, além de que é uma atividade compatível para o pequeno produtor, haja vista que o investimento inicial e a manutenção anual é relativamente 
baixo.

Figura 7: Valor da produção no Estado do Pará em R\$.

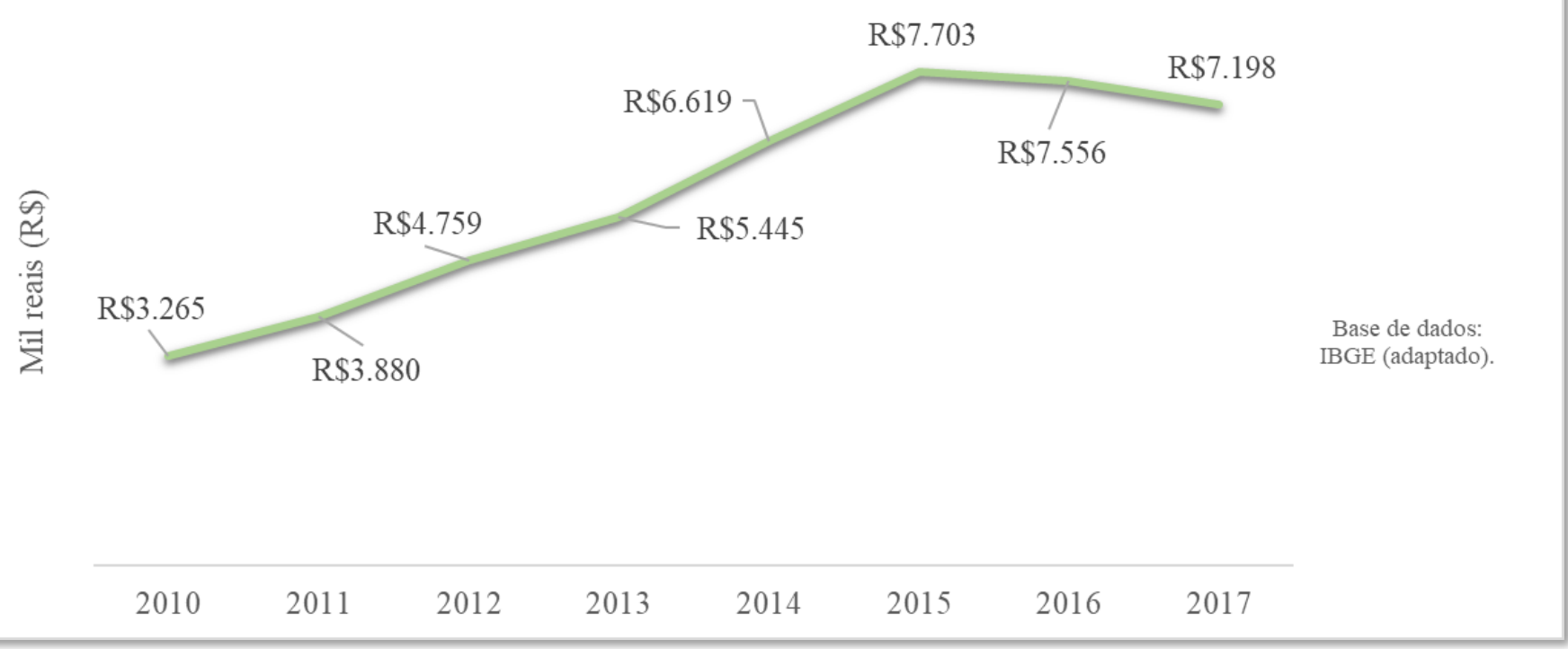

Fonte: Própria (2019).

A exportação de mel no Pará teve seu ápice no ano de 2018 com 47 kg líquidos e com a previsão de $40 \mathrm{~kg}$ líquidos para este ano de 2019. Ademais, no período de 2010 a 2016 não foi encontrado dados a respeito da exportação paraense de mel.

Uma possível justificativa para a baixa exportação do mel. Comparada com a produção que é uma média de 480 toneladas para uma exportação que não chega $100 \mathrm{~kg}$. Deve-se ao fato que para a exportação do mel, são necessários o cumprimento de alguns pré-requisitos técnicos que são exigidos para exportação e também a falta de produto inspecionado.

Como a produção de mel é artesanal e os produtores ainda atuam na informalidade porque os produtos ainda não são inspecionados pelas instituições de fiscalização de produtos de origem animal (SIF ou SIE). A venda é feita no mercado informal com a formação de preços ditados pelos compradores. E como essas empresas possuem estoque a compra não é regular. 
Figura 8: Exportação de mel natural no Estado do Pará.

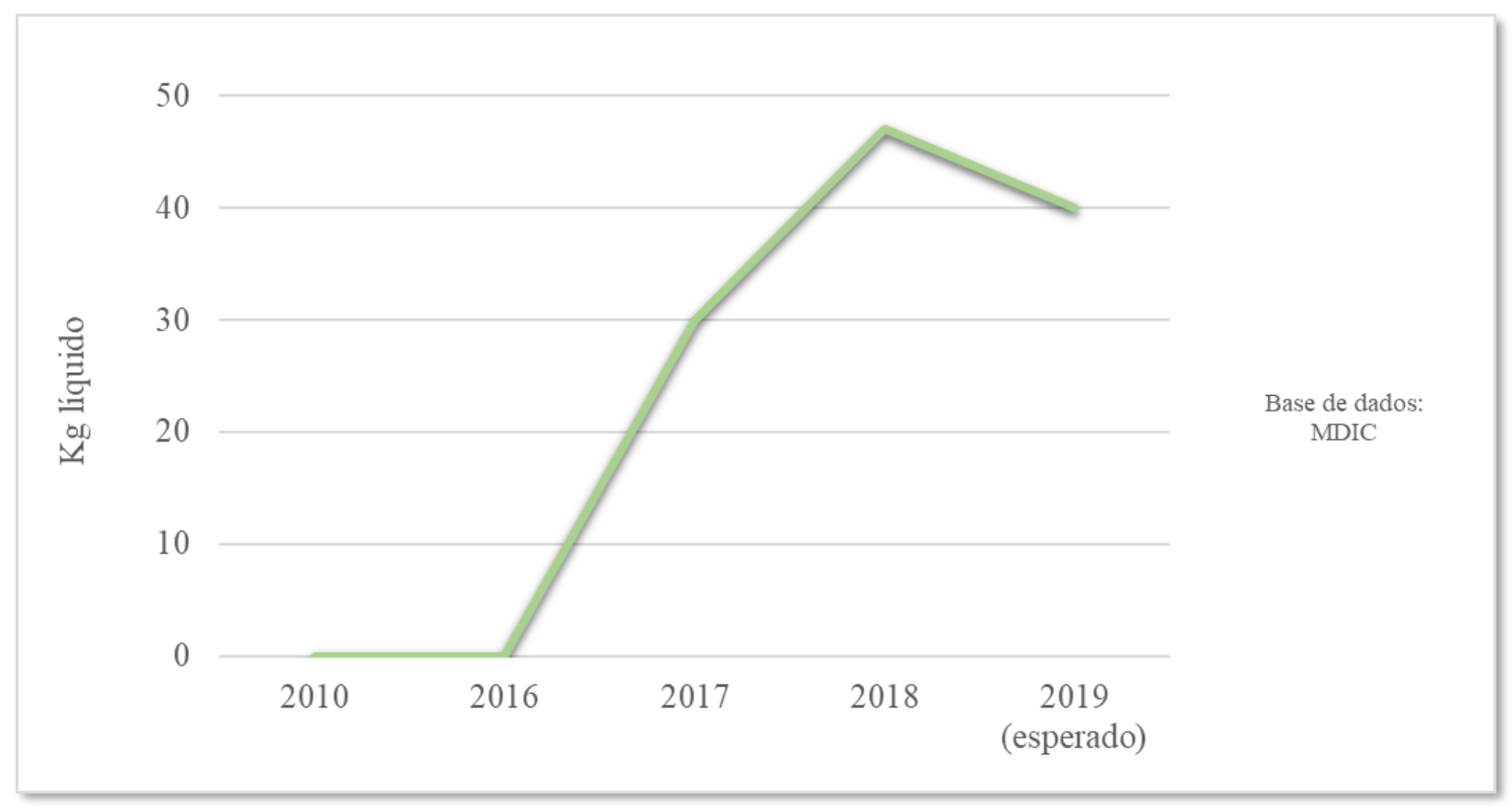

Fonte: Própria (2019).

Relacionado a venda do mel, os dados de 2014 a 2018 em Belém, Altamira, Breves e Gurupá mostram a variação dessa venda (figura 9). Realizada pelo IMAZON em diversos municípios do estado do Pará, e divulgadas no boletim de produtos florestais não madeireiros mensalmente.

Belém é o mercado onde o mel tem o preço com o maior valor agregado, o fato de vim de outros municípios o preço acrescenta as despesas de comercialização como frete, haja vista que Belém não apresenta nenhum estabelecimento produtor de mel. E como esta venda é repassada por atravessadores que compram o mel dos produtores. O valor final do produto é maior na feira de Belém, quando comparado a outros municípios como Altamira e Gurupá. Observa-se também a flutuação de preços na cidade de Belém, quando em 2017 apresentou o menor valor, pouco mais de $\mathrm{R} \$ 27,00$ o litro do mel. 
Figura 9: Preços dos produtos no ano de 2014 a 2018.

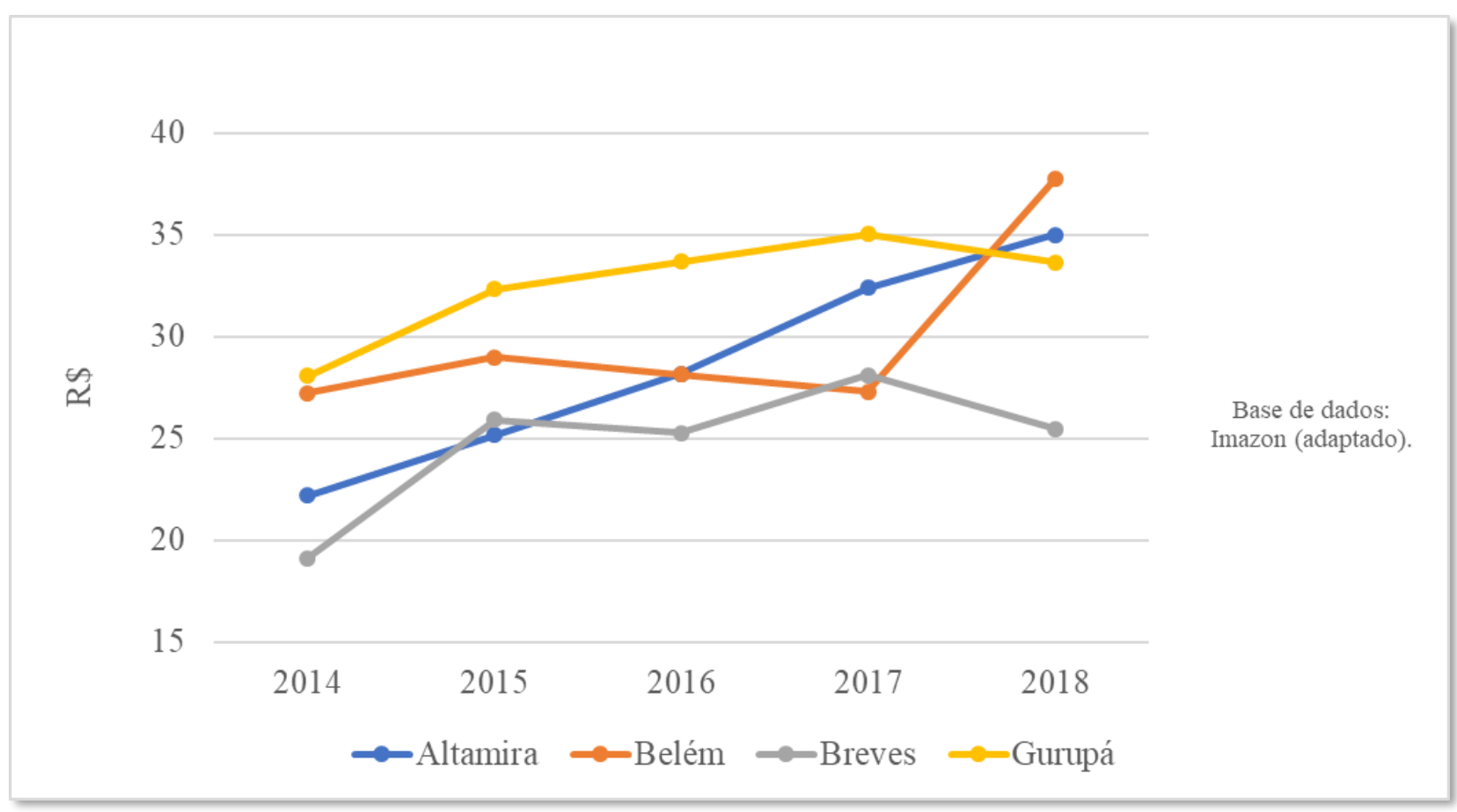

Fonte: Própria (2019).

Cabe ressaltar que este valor de venda é do mel do gênero Apis, pois seu valor é relativamente menor, visto que a produtividade do apiário é grande. Em relação ao mel de melípona, que a sua produtividade é menor. $\mathrm{O}$ valor do litro de mel pode custar 3 vezes mais que o mel de apis.

\section{Conclusões}

O mel produzido pelas abelhas é apenas o topo da pirâmide, pois o valor real destes insetos está na importância ecológica e ambiental que as mesmas fazer através da polinização.

O mercado paraense apresenta vários entraves, tais quais a dificuldade de conseguir o certificado do Serviço de Inspeção Federal, haja vista que o mel é produto de origem animal e sem esta certificação, faz com que muitos produtores vendam na informalidade.

A utilização do mel nas comidas gourmet é um indício de que a utilização do mesmo tende a crescer, logo, tende a aumentar a produção do mel pelos apicultores e meliponicultores do estado do Pará. 


\section{Referências}

ALMEIDA, Marco Antonio Dantas de et al. Apicultura: uma oportunidade de negócio sustentável. Salvador: SEBRAE. 2009. Disponível em: <http://www.bibliotecas.sebrae.com.br/chronus/ARQUIVOS_CHRONUS/bds/bds.nsf/E3CA 0B10F1061D878325766300685F92/\$File/NT00042B86.pdf>. Acesso em: 26/08/2019.

ADEPARÁ. Agência de defesa agropecuária do Estado do Pará. Disponível em: $<$ http://www.adepara.pa.gov.br/sites/default/files/LEI\%20N\%C2\%BA\%207.565-

2011_0.pdf>. Acesso em: 14/08/2019.

BALBINO, Valdir Antônio et al. Apicultura e responsabilidade social: desafios da produção e dificuldades em adotar práticas social e ambientalmente responsáveis. Ver. Eletrôn. De Administração. $\quad$ v. 21 , n. 2, p. 348-377, 2015. Disponível em: <https://www.redalyc.org/pdf/4011/401141534004.pdf>. Acesso em: 24/08/2019.

CASTRO, Antônio Maria Gomes de et al. Cadeia produtiva: marco conceitual para apoiar a prospecção tecnológica. In: XXII Simpósio de gestão da inovação tecnológica. 2002.

Disponível em:

<http://www.comexresponde.comexbrasil.gov.br/portalmdic/arquivos/dwnl 1197031881.pdf

$>$. Acesso em: 08/07/2019.

DUARTE, Rosineide Pontes. Custos e retorno da produção de mel para o apicultor no município de Cacoal Rondônia. Trabalho de Conclusão de Curso. Disponível em: $<$ http://www.ri.unir.br/jspui/bitstream/123456789/2048/1/TCC\%20pronto.pdf>. Acesso em: 25/08/2019.

MAIA, Ulysses Madureira. Diagnóstico da meliponicultura no Estado do Rio Grande do Norte. Dissertação. Disponível em: <http://repositorio.ufersa.edu.br/handle/tede/705>. Acesso em: 24/08/2019.

PASCHOALINO, Augusto et al. Limites e possibilidades para a apicultura na região central do Estado de São Paulo. Rev. de Adm. UFSM. v. 7, 2014. Disponível em: <https://www.redalyc.org/pdf/2734/273432632004.pdf>. Acesso em: 26/08/2019.

RIBEIRO, Kleber Ávila et al. Arranjo produtivolLocal (APL) como estratégia de potencializar as fronteiras mercadológicas do apicultor no perímetro de irrigação Senador Nilo coelho em Petrolina-PE. Rev. de Gestão, Finanças e Contabilidade. v. 3, n. 2, p. 99-120, 2013. Disponível em: <https://www.revistas.uneb.br/index.php/financ/article/view/230/386>. Acesso em: 26/08/2019.

SABBAG, Omar Jorge et al. Viabilidade econômica para produção de mel em propriedade familiar. Pesq. Agropec. Trop. Goiânia. v. 41, n. 1, p. 94-101, 2011. Disponível em: <http://www.scielo.br/pdf/pat/v41n1/a08v41n1.pdf>. Acesso em: 20/08/2019.

SANTOS, Raquel Leão et al. Levantamento da flora com potencial apícola e meliponícola no Estado do Pará. In: 22 Seminário PIBIC 2018 Embrapa Amazônia Oriental. Disponível em: <https://www.alice.cnptia.embrapa.br/handle/doc/1105980>. Acesso em: 10/08/2019. 
SILVA, G. F. da; VENTURIERE, G. C et al. Meliponicultura como alternativa de desenvolvimento sustentável: gestão financeira em estabelecimentos familiares no município de Igarapé-Açu, PA. In: XVI Congresso Brasileiro de Apicultura. 2006. Disponível em: $<$ https://ainfo.cnptia.embrapa.br/digital/bitstream/item/42470/1/ID42121.pdf>. Acesso em: 27/08/2019.

SILVA, Mayesse A. da et al. Sistema de informações geográficas no planejamento de uso do solo. Rev. Brasileira de Ciências Agrárias. v. 8, n. 2, p. 316-323, 2013. Disponível em: <https://www.redalyc.org/pdf/1190/119027922023.pdf>. Acesso em: 20/08/2019.

SOUZA, José Edmundo Accioly de. Agronegócio da apicultura: estudo da cadeia produtiva do mel em Alagoas. Dissertação (Mestrado em Desenvolvimento sustentável Regional) Universidade Federal de Alagoas, Maceió, 2006. Disponível em: <http://www.repositorio.ufal.br/handle/riufal/1124>. Acesso em: 21/08/2019.

VILELA, Sérgio Luiz Oliveira. Principais Resultados do Estudo da Cadeia Produtiva do Mel de Abelhas do Estado do Piaui: Pesquisa Socioeconômica. Rev. Cient. Prod. Anim. v. 2, n. 2, p. 249-259, 2000. Disponível em: 〈file:///C:/Users/User/Downloads/57-218-1-PB.pdf>. Acesso em: 02/08/2019.

WOLFF, Luis Fernando. Sistema de Produção de Mel para a Região Sul do Rio Grande do Sul. EMBRAPA. $2018 . \quad$ Disponível em: <https://www.infoteca.cnptia.embrapa.br/infoteca/bitstream/doc/1104382/1/Sistema26web.pd f>. Acesso em: 14/08/2019.

ZANDONADI, Diogo Altoé et al. Competitividade das exportações brasileiras de mel. Ver. Econômica do Nordeste. v. 37, n. 1, p. 1-17, 2005. Disponível em: <https://ren.emnuvens.com.br/ren/article/view/583/461>. Acesso em: 18/08/2019. 